\title{
Improve Township Cadres' Appraisal System in the E-government Environment
}

\author{
Dexiang Zhou ${ }^{1, a}$, Shihua $\mathrm{Li}^{2, \mathrm{~b}}$ \\ ${ }^{1}$ School of Marxism, Hohai University, Nanjing, 210098, China \\ ${ }^{2}$ School of Management and Engineering, Nanjing University, Nanjing, 210093, China \\ aemail:zhoudexiang7428@sina.com, bemail:lishihua88@163.com
}

Keywords: Township Cadres; Appraisal; Appraisal System; E-government

\begin{abstract}
Scientific cadre's appraisal system plays a very important role on the cadres' work evaluation. There are some defects in the township cadres' appraisal system in modern China, including appraisal system lacks of relevance and feasibility, appraisal process lacks of rationality and feedback, appraisal results lacks of openness and motivating in township cadres' appraisal. In order to improve township cadres' appraisal system accordance with the requirements of scientific concept of development in the e-government environment, we must repositioning appraisal subjects, scientifically set appraisal contents, correctly formulate appraisal methods, and effectively use appraisal results.
\end{abstract}

\section{Introduction}

The 17th National People's Congress of the Communist Party of China indicated that we need to improve cadres' appraisal system according to scientific concept of development, this is an important initiative to thoroughly implement the scientific concept of development. The development of our cadres' appraisal process indicates our cadres' appraisal experienced a process from partial to full, from single to integrated, from imperfect to gradually improved. The process as follows: regular appraisal in 1979, leader's annual appraisal in the counties in 1988, Central leadership cadres' annual appraisal in 1989, government leadership work performance appraisal in 1995, the implement of "Interim provisions of the Party and government leadership cadres' appraisal" in 1998, the implement of "Outline of deepening reform of personnel system" in 2000, and the implement of "Regulations of the Party and government leading cadres' work" provided the introduction of the six basic conditions of the Party and government leaders in 2008. However, there is no sound and comprehensive appraisal system to many township grassroots cadres, their appraisal system generally in the light of the county government level or a higher level of government cadres' appraisal standards. Township cadres directly facing the mass people, the particularity of their work determines the appraisal standards can not copy from governments above them. In particular, the carrying out and implying the scientific concept of development put forward higher requirements to township's township cadres. So, it is imperative to improve township cadres' appraisal system which embodies the requirements of the scientific concept of development.

\section{The scientific concept of development endows township cadres' appraisal with new meanings}

\subsection{The scientific township cadre' appraisal system embodies the essence of scientific development and highlights the concept of people-oriented}

The first meaning of the scientific concept of development is development, the core is people-oriented, the basic requirement is comprehensively, coordinated and sustainable development, the fundamental approach is co-ordination. A scientific township cadres' appraisal system must embodies the meaning of the scientific concept of development from the appraisal standards, appraisal methods and other related systems, and highlights livelihood of people in economic construction, political construction, cultural construction and social construction, and always serve the people, and resolutely oppose divorce themselves from the masses, the abuse of power, oppose formalism, bureaucracy and fraud. Consider whether represents fundamental 
interests of the overwhelming majority of people, raise the people's living standards as a measurement of all of their work performance. Do practical things about the most people concerns, the direct interests of people, and strive to realize the people' common prosperity and comprehensive development.

\subsection{The scientific township cadres' appraisal system reflects the standard of scientific development, highlights the ability of govern}

The scientific concept of development emphasizes the development of comprehensive, coordinated and sustainable, which put forwards higher requirements to the Party's ability of govern. We need to enhance the coordination of development, change patterns of development in economic construction; to protect people's rights bitterly, expand citizens' orderly political participation in political construction; to improve the culture quality of people and expand the scope of public cultural services ,make the socialist core value system deeply rooted in culture construction; to the improve people's live standard comprehensively in social construction; to reexamine the relationship between man and nature, economic development and environmental protection and strongly advocated building a resource-saving and environment- friendly society in ecological construction. To achieve these goals, the key is to improve township cadres' ability to govern, and constantly improve their leadership style and methods of work.

\section{Defects in township cadres' appraisal system in modern China}

\subsection{The township cadres' appraisal system lacks of relevance and feasibility}

The main standard of the current township cadres' appraisal are "The temporarily regulations of civil servants" and "The temporarily provisions of civil servants' appraisal”. These two appraisal standards have been implemented for nearly 20 years and have lost their relevance and feasibility" The temporarily regulations of civil servants" states: "the department heads responsible for national civil servants' appraisal. The administrative institutes set a committee or a team that responsible for the civil servants' annual appraisal under the lead of department heads."[1] We can found that the regulation is not clear in which who is responsible for the cadres' appraisal in the end, and the relationship between appraisal committee and administrative heads is also not clear. In fact, the annual appraisal of township cadres is often carried out by the person in charge of the Party committee or government under the personnel department, and the appraisal committee' function is negligible.

"The temporarily provisions of civil servants' appraisal” states: “the appraisal of civil servants including morality, ability, diligence, performance, and emphasizes performance."[2] But it is a principled defines, lacks of specific contents. In practice, the appraisal content is often lacks of organic links with the goals, mission and tasks of the civil servant. Morality and ability are difficult to quantify, even diligence and performance are also can't clearly to quantify because of the characteristics of the civil servants' work. These results in the cadres' appraisal lacks of relevance and feasibility.

\subsection{The township cadres' appraisal process lacks of rationality and feedback}

The results of the annual appraisal of township cadres is purely qualitative with four grades: "excellent”, “competent”, "basically competent" and "incompetent", and also that provide that excellent ratio is generally $10 \%$,can not exceed $15 \%$ of the total number[3]. In practice, the vast majority people are apprised of "competent" in the annual appraisal of township cadres, the "incompetent" person always very small since the implementation of the civil servants' appraisal system. The persons who obtained "competent" always did well in morality work performance, but a part of which did not well, because the appraisal results is only qualitative and not quantitative. They are entitled the same treatment, which certainly blows the enthusiasm of some excellent person. According to “The temporarily provisions of civil servants' appraisal” the appraisal results of township cadres in accordance with these procedures: the department head put forwards appraisal opinion which based on the opinions of the masses, routinely examinations and individuals concluded, then audit by appraisal committee or committee team, finally determine the appraisal grade by department head. This operation is equal to give the decision right of the result of appraisal to the department head, which will inevitably have problems in practice. In practice, the best candidates' determining often based on the form of "democratic evaluation", but "democratic 
evaluation" always lacks of the basis of examination and quantitative assessment criteria. So it is generally based on impression and relationship, some even "take turns" in order to avoid conflicts, the result is that the appraisal is not based on morality ability, diligence and performance, but based on impression, relationship, even luck. Therefore, excellent person can not convince the public, and sometimes results in conflicts between the civil servants.

\subsection{The township cadres' appraisal process lacks of openness and motivating}

"The temporarily regulations of civil servants" does not provide a system of notification of the appraisal results. "Suggestion about strengthen civil servants' examination” only provides the publicity of the grade of excellent person, the other person and the final appraisal result still do not have a clear system of notification. Affected by the backward concepts, the non-authority appraisal result and the limited administrative resources, township government lacks of incentives for excellent civil servants who obtained appraisal result of excellent grade and lacks of punish measures to the incompetent ones. The civil servants' promotion actually doesn't associate with appraisal result. In addition, the appraisal of township cadres always emphasizes significant results while ignores potential results, emphasizes personal performances while ignores group achievements, emphasizes the final examination while ignores usual examinations. All of these seriously affected the quality and effectiveness of the appraisal.

\section{Measures to improve township cadres' appraisal system in the e-government enviroment}

Township cadres' appraisal system should includes four subsystems: system of appraisal subject, system of appraisal index, system of appraisal method and system of the use of appraisal results. By establishing and improving the scientific decision-making mechanism, the appraisal mechanism, the performance management mechanism, supervision and incentives mechanism, to solve the difficulties of "Who is to appraisal ", "how to appraisal" and "how to use the appraisal results", so as to ensure the implementation of the scientific concept of development.

\subsection{Repositioning appraisal subjects}

Repositioning appraisal subjects is to solve the problem of who is going to appraisal. Scientifically determine the appraisal subjects, we must adhere to the principle recognized by the masses, and promote democracy, expand the scope of participation by the masses. Expand democracy, enhance transparency, and improve the credibility by "democratic evaluation" and assessment of the satisfaction of the masses [4]. It will help to enhance the enthusiasm of the masses to participate in the cadres' appraisal and strengthen the supervision to the work of the cadres' appraisal. Especially to the examination of qualitative indicators, we must actively explore the establishment of public appraisal system, adopt method of public appraisal, carry out opinion survey in a wide range, and truly make the people' satisfaction to the important and effective appraisal standards. It will help to promote the leading cadres become "eyes up" to "eyes down". Establish and improve the cadres' appraisal based the mass's opinions, not only can effectively overcome the drawbacks that the result of cadres' performance appraisal determine by superior and solve the problem of performance appraisal of the township cadres, but also guide township cadres focus on public opinions of the masses, unify the responsibility to superior and to the mass people.

\subsection{Scientifically set appraisal contents}

Scientifically set appraisal contents are to solve the problem of what to appraisal. Only scientifically and reasonably set appraisal contents to solve the problem what to appraisal, can we make the appraisal more targeted, and the appraisal results more accurately reflect the actual work of the township cadres. When we set appraisal contents, we should not only see the achievements of economic construction, but also see the results of achievements social progress; not only emphasize current development, but also emphasize the sustainability of development; not only depend on the achievements of economic and social development, but also depend on the outcome of the Party building. Especially in the formulation of economic development indicators, we must not only pay attention to the total economy and the speed of economic development, but also to pay attention to the quality and efficiency of economic development and the protection of resources and environment. Only in this way, can make township cadres especially leading cadres truly realistic and pragmatic, and establish correct view of achievements, consciously adhere to the scientific concept of development. 


\subsection{Correctly formulate appraisal methods}

Correctly formulate appraisal methods is to solve the problem of how to appraisal. It is very important to scientifically build appraisal system. We must establish and improve cadres' performance management mechanism based on work performance. Vigorously pursue township cadres' work performance management which based on the actively pursuing township cadres' job target responsibility system. Adhere to focusing on work performance and duties' fulfilling, transform township cadres' appraisal from "based on position management" to "based on responsibility management”. We must formulate different responsibility goals according to different duties, and decompose and quantify these responsibility goals, so as to make their easy to operate. By the decomposition of the target responsibility, make all of the township cadres diligent and responsible on the post, by first-class style of work to create first-class job performance. By taking the combination of quantitative analysis and qualitative analysis, make classification examination.

\subsection{Effectively use appraisal results.}

Effectively use appraisal results are to solve the problem of how to use the appraisal results. The ultimate purpose of scientific appraisal is to implement a measure of "promoting the excellent person but eliminating the inferiors" of township cadres. [5] We must effectively apply the appraisal results to the whole process of township cadres' promotion or demotion and supervision. Only combined the appraisal results with appointment of township cadres, can we ensure the impartiality election, effectively curb the malpractices of appointment and formulate an open, equal, competitive, merit-based employment environment. Consider the conclusion of the work performance and moral performance as the basis of cadres' appointment. Through strict implementing of rewards and punishments, to earnestly solve the problem of the same results of "do much and do less", "do well and do badly”, "do and not do". Fully mobilize the enthusiasm of township cadres to form an employment mechanism of encouraging competition, "survival of the fittest”, full of vigor and vitality, and a healthy atmosphere of hardworking.

\section{Conclusion}

In short, the sound and perfect township cadres' appraisal system is very important to the majority of township cadres who work at the grassroots to comprehensively implement the scientific concept of development, establish a correct view of achievements, and maintain vigor and vitality. There is no doubt that highly qualified township cadres is of importance for the township's economy development, social development, progress of political civilization and improvement of people' living standards. All of which are related to the success or failure of the construction of a socialist harmonious society and the building of a well-off society. However, construct a scientific, sound and perfect township cadre' appraisal system is not very easy, it will takes us much time to explore, summarize and innovate in future practice.

\section{Acknowledgement}

This work was financially supported by the scientific research innovation project in Jiangsu province in 2012 (CXZZ12_0222).

\section{References}

[1] The temporarily regulations of civil servants [Z]. Executed in October 1, 1993.

[2] The temporarily provisions of civil servants’ appraisal [Z]. Executed in March 8, 1994.

[3] Y.M. Wang, H. Yang. Reflections about the construction of the county (district) appraisal system of leading cadres [J].Leading Science, 2012(7)45-48.

[4] B.X. Liu. Thinking of advancing scientific assessment of cadres [J].Theory Exploration, 2011(2) 9-11.

[5] J.F. Zhang. Building leadership cadres’ appraisal system [J].People’s Forum, 2010(6) 46-47. 